Pak. J. Agri. Sci., Vol. 53(1), 201-208; 2016

ISSN (Print) 0552-9034, ISSN (Online) 2076-0906

DOI: $10.21162 / P A K J A S / 16.4179$

http://www.pakjas.com.pk

\title{
RELATIONSHIP OF COLLEMBOLA POPULATION WITH DIFFERENT ABIOTIC FACTORS IN AN AGRICULTURAL ECOSYSTEM OF FAISALABAD, PUNJAB, PAKISTAN
}

\author{
Muhammad Usman Asif ${ }^{1, *}$, Sohail Ahmed ${ }^{1}$, Rashad Rasool Khan ${ }^{1}$ and Muhammad Atiq ${ }^{2}$ \\ ${ }^{1}$ Department of Entomology, University of Agriculture, Faisalabad, Pakistan; \\ ${ }^{2}$ Department of Plant Pathology, University of Agriculture, Faisalabad, Pakistan. \\ "Corresponding author's e-mail: uakhan1987@ hotmail.com
}

\begin{abstract}
In the present studies, Collembola populations were followed for one year in multiple crops agroecosystem of Faisalabad, Pakistan. Four crops, viz., sugarcane, cotton, clover and wheat were selected. Sampling was done fortnightly by installing pitfall traps in each crop area. The results revealed that maximum mean abundance of Collembola was found in clover (36.74) followed by sugarcane (29.15), cotton (20.79) and wheat (16.52). Four species of Collembola (Isotoma decorata, Xenylla indus, Seira indra and Sminthurus mime) were abundant in cotton followed by three (Xenylla indus, Seira indra and Sminthurus mime) in sugarcane and two (Xenylla indus and Seira indra) each in clover and wheat. The proportionate percentage of the abundance of Xenylla indus was 65\% followed by $20 \%$ of Seira indra, $13 \%$ of Isotoma decorata and $2 \%$ of Sminthurus mime throughout the sampling period taking together all the crops. The principal component analysis showed significant effect of soil moisture and soil $\mathrm{pH}$ on the abundance of Collembola while the effect of soil temperature, relative humidity and organic matter was non-significant. The abundance of Collembola was positively correlated with soil moisture and organic matter in all the crops, soil temperature in wheat, relative humidity in sugarcane and cotton, soil $\mathrm{pH}$ in cotton while negatively correlated with soil temperature in sugarcane, cotton and clover, relative humidity in clover and wheat, soil $\mathrm{pH}$ in sugarcane, clover and wheat.

Keywords: Collembola, biodiversity, soil fauna, agronomic crops, abiotic factors
\end{abstract}

\section{INTRODUCTION}

Soil is one of the most essential and diverse natural habitat of biodiversity on earth. Soil fauna constitute $23 \%$ of the total diversity of living organisms (Decaens et al., 2006). Among these soil fauna, Collembola is reported to dominate in most kinds of soils (Brahmam et al., 2010; Zhu et al., 2010; Abbas, 2012). Their high abundance makes them significant contributors to several processes of soil, such as material and energy cycles, and formation of soil ( $\mathrm{Vu}$ and Nguyen, 2000). Collembola are also particularly sensitive to environmental changes, and therefore thought to be an excellent bioindicator (Hopkin, 1997; Jucevica and Melecis, 2006; Xu et al., 2009). Environmental changes such as variation in the soil moisture, precipitation, drought, global warming, soil $\mathrm{pH}$ and soil temperature are likely to cause changes in the density, diversity, survival, behaviour, activity and reproduction of Collembola (Loring, 1981; Bauer and Christian, 1993; Wolters, 1998; Pflug and Wolters, 1998; Choi et al., 2002, Ke et al., 2004).

Several studies indicated the effects of abiotic factors on the abundance, distribution and activity of Collembola in sitespecific ecosystems. Many of these studies included effects of combinations of edaphic and meteorological factors such as soil moisture (Choi et al., 2002; Choi et al., 2006; Schultz et al., 2006; Abbas and Parwez, 2012), soil temperature (Frampton et al., 2001; Karoline et al., 2010; Kardol et al., 2011; Begum et al., 2011), soil organic matter (Mussury et al., 2002; Muturi et al., 2009; Karoline et al., 2010), relative humidity (Loring, 1981; Gope and Ray, 2012), soil pH (Ke et al., 2004; Begum et al., 2014), rainfall (Ferguson and Joly, 2002; Lensing et al., 2005), vegetation cover (Hansen, 2000; Bandyopadhyaya et al., 2002; Abbas, 2012) and crop type (Kanal, 2004) on Collembola. These studies also suggest that there is ample scope of investigation on these abiotic factors in context of Collembola to envisage the challenges of climatic changes.

Variation in the abundance of Collembola in response to different abiotic factors although have been documented in grassland, pastures, forest and desert but their abundance / density and dynamics in an agricultural ecosystem have not been studied extensively. The low soil $\mathrm{pH}$, high soil moisture, rainfall, high organic matter had positive influence on the abundance of Collembola in a mixture of different clovers (Trifolium angustifolium, T. strictum, T. repens, $T$. glomeratum and $T$. campestre), rice, wheat and vegetables (Sousa et al., 2004; Zhimomi et al., 2009; Muturi et al., 2009; Begum et al., 2014). The density of Collembola in a forest and agroecosystem significantly increased with soil temperature. However, soil $\mathrm{pH}$ had a negative impact on the 
density of Collembola (Paul and Nongmaithem, 2011). Other examples include studies in cotton fields (Brahmam et al., 2010), sugarcane (Sajjad et al., 2012), maize (Pineda et al., 2012), alfalfa (Phoofolo et al., 2010) and citrus orchards (Silva et al., 2010). However, these studies did not specifically focus upon relationship among soil, Collembola, abiotic factors and components of agroecosystem of a particular area.

A few studies on the taxonomy, abundance and seasonal dynamics of Collembola in Pakistan encircle a specific site and not a whole agroecosystem (Ashraf, 1966; Masud, 1971; Qadeer, 1974; Suleman and Jan, 1981). This information leads to initiate the present studies with an overall objective of determining base line data of Collembola fauna in different agronomic crops in relation to environmental changes in agroecosystem of Faisalabad, Pakistan.

\section{MATERIALS AND METHODS}

The study was conducted in Faisalabad District, covering an area of 5, $856 \mathrm{~km}^{2}$ in the Central Punjab, Pakistan, $\left(73.0790^{\circ}\right.$ E, $31.4180^{\circ} \mathrm{N}$ ) where the sugarcane, clover, maize, wheat and vegetables (tomato, cauliflowers and cucurbits) are the major crops. The present study was conducted during the period of March 2012 to April 2013.

Sampling of Collembola was done in a sugarcane (Saccharum officinarum) from March to July 2012, whereas, in cotton (Gossypium hirsutum) from July to November 2012, in clover (Trifolium alexandrinum) from November to March 2012-2013 and in wheat (Triticum aestivum) from December to April 2012-2013. One acre area for each crop was selected and then divided into four equal plots. Sampling was done fortnightly by installing four pitfall traps $10 \mathrm{~m}$ apart in a quadrat in each divided plot (total of 16 traps on each sampling occasion). The pitfall traps were plastic cups $(5 \mathrm{~cm}$ in diameter and $8 \mathrm{~cm}$ deep), buried in the soil with its upper end leveling the ground, to facilitate insect fall in them. One fourth of the pitfall trap was filled with $25 \%$ ethylene glycol. In each crop, the traps were operated consecutively for 72 hours after every 15 days for the sampling of Collembola during the whole growing period of the crops. Most prevalent and abundant collembolans from all sampling occasions in each crop were identified up to the species level by using taxonomic key (Ashraf, 1966). Abiotic factors that includes soil temperature, relative humidity, soil moisture, soil $\mathrm{pH}$ and organic matter were also determined fortnightly from each crop at the site of pitfall installment.

Soil temperature at the surface of the ground was measured by placing the thermometer flat on the ground for one minute and relative humidity was determined by a Chinese analog Thermo-Hygrometer (Shenzhen Ideal Industrial Model TH101). EcoScan pH meter was used to determine the $\mathrm{pH}$ of soil in each crop at each sampling time by following the method of Bates (1954) and Soil moisture was determined by using the method of Reynolds (1970). The $\left(\mathrm{H}_{2} \mathrm{O}_{2}\right)$ hydrogen peroxide digestion method was used to determine the organic matter content of soil sample from each crop area through oxidation and destruction (Schumacher, 2002).

Collembolan abundance between different crops was compared through multiple sample comparison using ANOVA (Statgraphics, 2009). Collembola species abundance and other basic parameters were computed with PAST program (Hammer et al., 2001). Correlation of abundance with individual abiotic factors was computed through StatSoft Statistica (StatSoft, 2011). Principle component analysis was performed using CANOCO 4.5. All the species data in this analysis were log transformed and down weighting of rare species was applied (Ter Braak and Smilauer, 2002).

\section{RESULTS}

Maximum mean abundance of Collembola (36.74) was found in clover while wheat (16.52) harbored the lowest abundance of Collembola. However, total number of species was highest (4) in cotton followed by sugarcane (3), clover and wheat (2 in each). Shannon Weiner's diversity was lowest in wheat (0.45) while it was highest in cotton (0.98). ANOVA of abundance of Collembola in different crops from the period of March 2012 - April 2013 showed a statistically significant difference in the abundance of Collembola between the four crops at $95 \%$ confidence level $(F=18.33, p=0.000)$. Multiple range test showed that the mean abundance of Collembola in clover was significantly different from the abundance in cotton, wheat and sugarcane (Table 1).

Table 1. Mean abundance, species richness, diversity and evenness of Collembola in four agronomic crops.

\begin{tabular}{lcccccc}
\hline Crops & $\mathbf{N}$ & $\mathbf{S}$ & $\mathbf{D}$ & $\mathbf{1 - D}$ & $\mathbf{H}$ & $\mathrm{e}^{\mathbf{H} / \mathbf{S}}$ \\
\hline Sugarcane & $29.15 \mathrm{~b}$ & 3 & 0.66 & 0.33 & 0.58 & 0.59 \\
Cotton & $20.19 \mathrm{c}$ & 4 & 0.46 & 0.53 & 0.98 & 0.67 \\
Clover & $36.74 \mathrm{a}$ & 2 & 0.57 & 0.42 & 0.62 & 0.93 \\
Wheat & $16.52 \mathrm{c}$ & 2 & 0.73 & 0.27 & 0.45 & 0.78 \\
\hline
\end{tabular}

$\mathrm{N}=$ Mean Abundance, $\mathrm{S}=$ Richness, $\mathrm{D}=$ Dominance, $1-\mathrm{D}=$ Simpson's diversity index, H= Shannon Weiner's diversity index, $\mathrm{e}^{\mathrm{H} / \mathrm{S}}=$ Evenness

The maximum abundance of Collembola in sugarcane was observed in the months of March (39.65 per trap) and April (39.18 per trap) and minimum abundance was observed in the months of June (21.87 per trap) and July (17.25 per trap) while in cotton abundance of Collembola was almost similar throughout the sampling months, however, increased abundance was observed in the months of October (22.09 per trap) and November (21.84 per trap). In case of clover, 
maximum abundance of Collembola was found in the month of March (43.06 per trap) as well as in the month of December (42.43 per trap) while in wheat, maximum abundance was found in the month of April (22.65 per trap) and lowest abundance was found in the month of December (12.75 per trap). Shannon diversity was lowest in wheat (0.37-0.42) from the month of December 2012 to April 2013 while highest (0.84-0.99) in cotton from the month of July to November 2012 (Figs. 1 and 2).

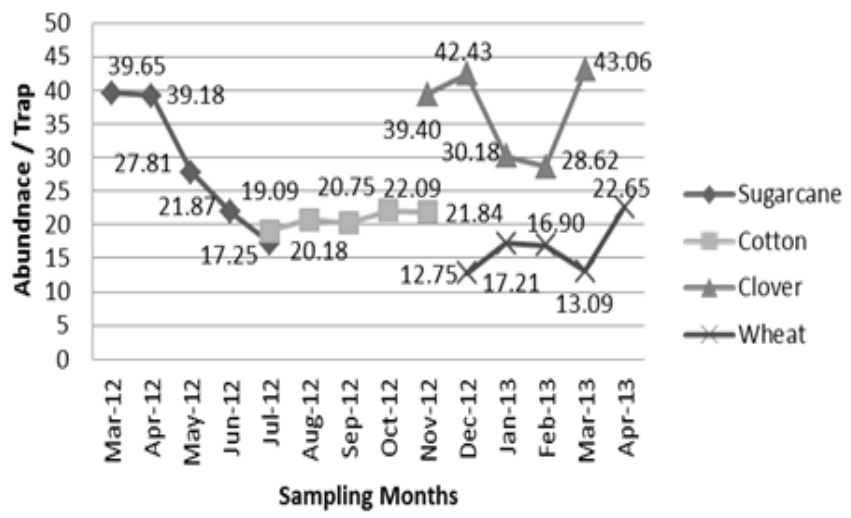

Figure 1. Overall abundance of Collembola across the year in different crops.

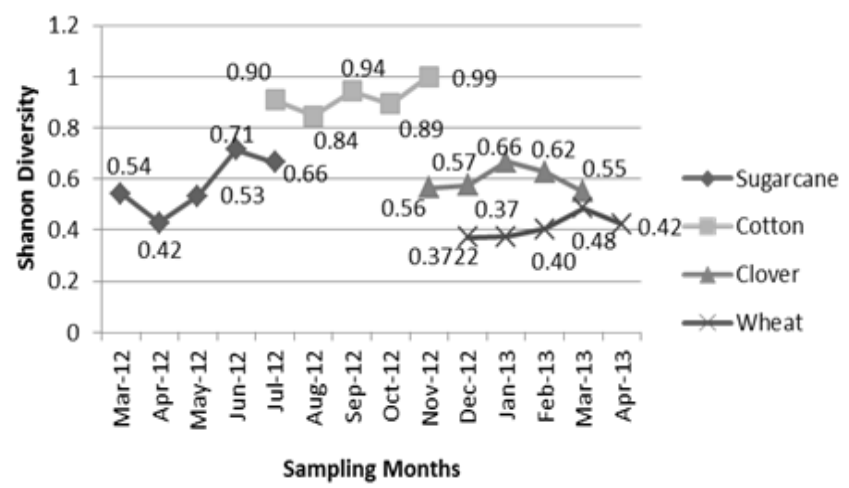

Figure 2. Collembola diversity across the year in four different crops.

Four species i.e. Isotoma decorata, Xenylla indus, Seira indra and Sminthurus mime were abundant in cotton followed by three ( $X$. indus, $S$. indra and $S$. mime) in sugarcane and two each $(X$. indus and $S$. indra) in clover and wheat. $I$. decorata was the most abundant species in cotton (63\%) followed by $X$. indus (24\%), S. mime (7\%) and $S$. indra (6\%). In case of sugarcane, $X$. indus was the most abundant (79 \%) followed by S. indra (19\%) and S. mime (2\%). The proportionate percentage of the abundance of $X$. indus was $68 \%$ and $83 \%$ followed by $32 \%$ and $17 \%$ of $S$. indra in clover and wheat. The ANOVA of abundances of Collembola species in different crops from the period of March 2012 - April 2013 showed a statistically significant difference in the abundance of $X$. indus $(F=19.34, p=$ $0.000), S$. indra $(F=62.42, p=0.000), I$. decorata $(F=$ $375.13, p=0.000)$ and $S$. mime $(F=11.88, p=0.000)$ between the four crops at $95 \%$ confidence level. The mean abundance of $X$. indus and $S$. indra was significantly highest in clover (25.06 and 11.67) while lowest (5.01 and 1.32) in cotton. I. decorata was only found in cotton crop and its mean abundance was 13.10. S. mime was only found in cotton and sugarcane and its abundance means were 1.35 and 0.65 (Fig. 3).

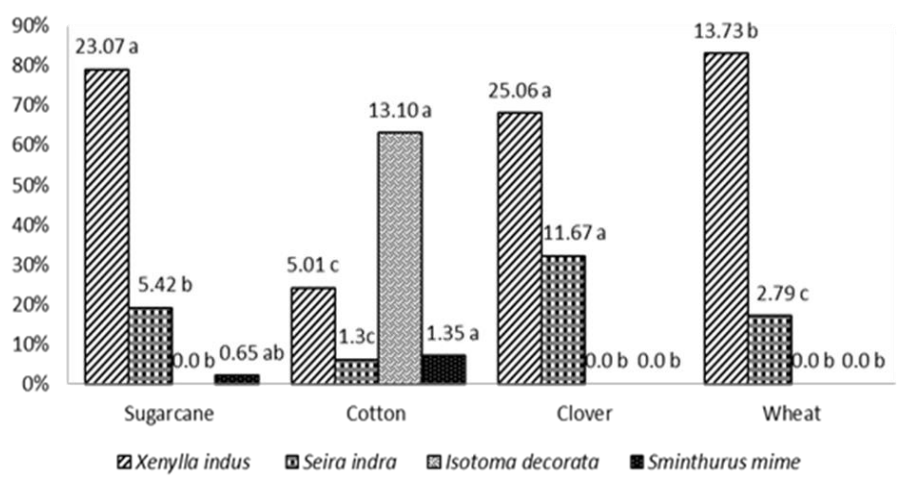

*Abundance means of same species in different crops that do not share a similar letter are statistically significant.

Figure 3. Difference in abundance of Collembola species in different crops.

Seasonal abundance of four different species of Collembola i.e. X. indus, $S$. indra, I. decorata and $S$. mime in different months throughout the year is shown in Fig. 4. X. indus was highest in the month of April 2012 followed by March 2012 and December 2012, S. indra in January 2013 and March 2012, I. decorata in October 2012 and S. mime in August 2012. X. indus was the most dominant one and represented more than one half $(65 \%)$ of the Collembola species abundance sampled throughout the year followed by $S$. indra (20\%), I. decorata (13\%) and S. mime (2\%) (Fig. 5).

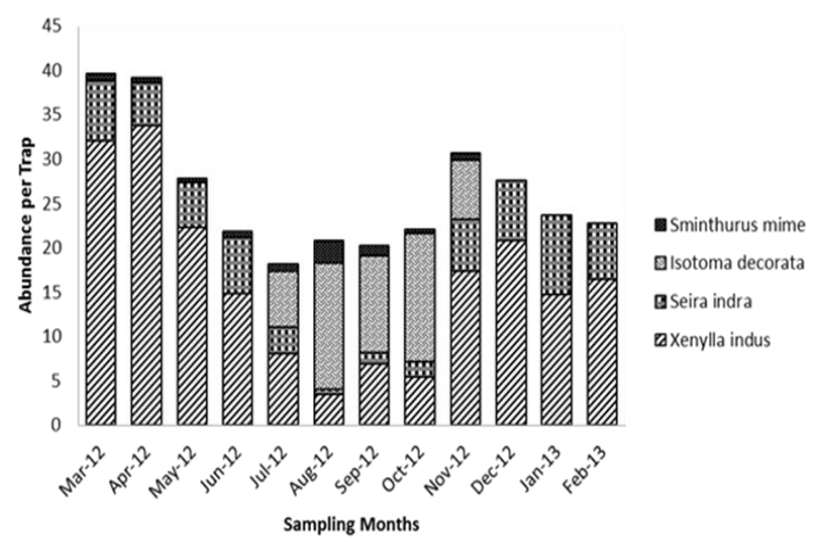

Figure 4. Seasonal abundance of different species of Collembola throughout the year. 


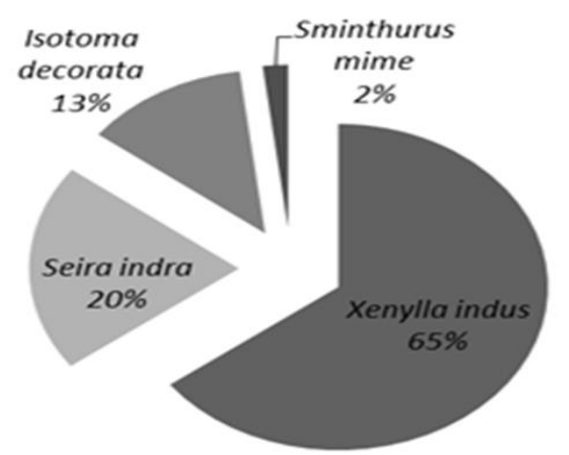

Figure 5. Abundance pie chart of different Collembola species over the year.

The abundance of Collembola showed strong positive correlation with soil moisture in sugarcane $(r=0.959, p=$ $0.0002)$, cotton $(r=0.7186, p=0.0036)$ and wheat $(r=$ $0.918, p=0.0081)$ while a weak positive correlation $(r=$ $0.054, p=0.7931$ ) was observed in clover. Soil temperature was strongly negatively correlated with Collembola abundance in sugarcane $(r=-0.964, p=0.0579)$ and cotton $(r=-0.795, p=0.0430)$ while a weak negative correlation was observed in clover $(r=-0.233, p=0.0636)$. In wheat crop, strong positive correlation of Collembola abundance was observed $(r=0.649, p=0.6273)$. Relative humidity was weakly positively correlated with Collembola abundance in sugarcane $(r=0.450, p=0.2855)$ and cotton $(r=0.418, p=$ $0.0416)$ while a weak negative correlation was observed in clover $(r=-0.207, p=0.5235)$ and wheat $(r=-0.413, p=$ 0.7291) crop. Strong positive correlation of Collembola abundance with organic matter was observed in sugarcane $(r$ $=0.652, p=0.4093)$ and cotton $(r=0.641, p=0.0375)$ while a weak positive correlation was observed in clover $(r$ $=0.379, p=0.2101)$ and wheat $(r=0.126, p=0.8737)$. Strong negative correlation of Collembola with soil $\mathrm{pH}$ was observed in sugarcane $(r=-0.768, p=0.8613)$ and clover $(r$ $=-0.835, p=0.0223$ ) while weak negative correlation was observed in wheat $(r=-0.331, p=0.9286)$. In contrast, weak positive correlation between Collembola abundance and soil $\mathrm{pH}$ was observed in cotton $(r=0.047, p=0.1022)$ crop (Table 2).

The ANOVA regarding the effect of abiotic factors on the abundance of Collembola by principal component analysis (PCA) showed significant effect of soil moisture $(F=5.64, p$ $=0.01)$ and soil $\mathrm{pH}(F=11.64, p=0.00)$ on the abundance of Collembola while the effect of soil temperature $(F=2.11$, $p=0.14)$, relative humidity $(F=1.23, p=0.28)$ and organic matter $(F=0.23, p=0.67)$ was non-significant. The PCA showed axis 1 with eigen values of (0.0371) and axis 2 with eigen values of (0.024). Axis 1 correlated mainly with $(r=$ $0.643)$ soil moisture and axis 2 with relative humidity $(r=$ 0.662 ). These two axis explained $37 \%$ and $39 \%$ of the total variance, respectively. The PCA revealed that the $X$. indus was correlated mainly with soil moisture, I. decorata with soil $\mathrm{pH}$, S. indra with organic matter and $S$. mime with soil temperature. Relative humidity was the least weighted factor to show correspondence by Collembola species abundance. $X$. indus was the most abundant species in sugarcane, clover and wheat and it was less affected by soil temperature, relative humidity, soil $\mathrm{pH}$ and organic matter. $S$. indra and $X$. indus were closely correlated to each other while negatively correlated with $S$. mime and I. decorata (Fig. 6).

Table 2. Correlation and regression values of different meteorological factors in relation to Collembola abundance in (A) sugarcane and cotton crops (B) clover and wheat crops.

\begin{tabular}{|c|c|c|c|c|c|c|}
\hline \multirow[t]{2}{*}{ Parameters } & \multicolumn{3}{|c|}{ Sugarcane } & \multicolumn{3}{|c|}{ Cotton } \\
\hline & $r$ & $p$ & Regression equation & $r$ & $p$ & Regression equation \\
\hline \multicolumn{7}{|c|}{ 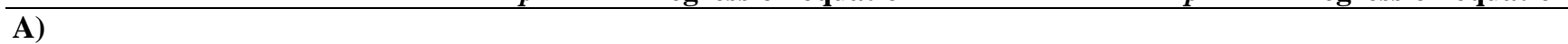 } \\
\hline Soil Moisture & 0.9596 & $0.0002 * *$ & $y=4.473+1.7506 x$ & 0.7186 & $0.0036 * *$ & $y=17.666+0.2744 x$ \\
\hline Soil Temperature & -0.9646 & $0.0579^{\mathrm{NS}}$ & $y=76.049-1.6059 x$ & -0.7954 & $0.0430 * *$ & $y=24.663-0.1483 x$ \\
\hline Relative Humidity & 0.4503 & $0.2855^{\mathrm{NS}}$ & $y=7.565+0.4152 x$ & 0.4188 & $0.0416^{* *}$ & $y=15.673+0.0777 x$ \\
\hline Soil pH & -0.7684 & $0.8613^{\mathrm{NS}}$ & $y=676.87-88.210 x$ & 0.0477 & $0.1022^{\mathrm{NS}}$ & $y=9.934+1.4367 x$ \\
\hline Organic Matter & 0.6529 & $0.4093^{\mathrm{NS}}$ & $y=-22.02+73.724 x$ & 0.6414 & $0.0375 * *$ & $y=18.272+3.531 x$ \\
\hline \multicolumn{7}{|c|}{ B) } \\
\hline \multirow[t]{2}{*}{ Parameters } & \multicolumn{3}{|c|}{ Clover } & \multicolumn{3}{|c|}{ Wheat } \\
\hline & $r$ & $p$ & Regression equation & $r$ & $p$ & Regression equation \\
\hline Soil Moisture & 0.0546 & $0.7931^{\mathrm{NS}}$ & $y=34.000+0.1793 x$ & 0.9182 & $0.0081 * *$ & $y=-12.947+2.0467 x$ \\
\hline Soil Temperature & -0.2332 & $0.0636^{\mathrm{NS}}$ & $y=43.378-0.5438 x$ & 0.6495 & $0.6273^{\mathrm{NS}}$ & $y=5.0795+0.8234 x$ \\
\hline Relative Humidity & -0.2074 & $0.5235^{\mathrm{NS}}$ & $y=46.574-0.1348 x$ & -0.4133 & $0.7291^{\mathrm{NS}}$ & $y=25.042-0.1318 x$ \\
\hline Soil pH & -0.8355 & $0.0223 * *$ & $y=319.34-37.8065 x$ & -0.3318 & $0.9286^{\mathrm{NS}}$ & $y=134.27-16.1984 x$ \\
\hline Organic Matter & 0.3790 & $0.2101^{\mathrm{NS}}$ & $y=17.168+21.2687 x$ & 0.1261 & $0.8737^{\mathrm{NS}}$ & $\mathrm{y}=3.048+17.6629 \mathrm{x}$ \\
\hline
\end{tabular}

$r=$ Correlation values; $* *=$ Significant $(\mathrm{p}<0.05) ; \mathrm{NS}=$ Non-significant $(\mathrm{p}>0.05)$ 


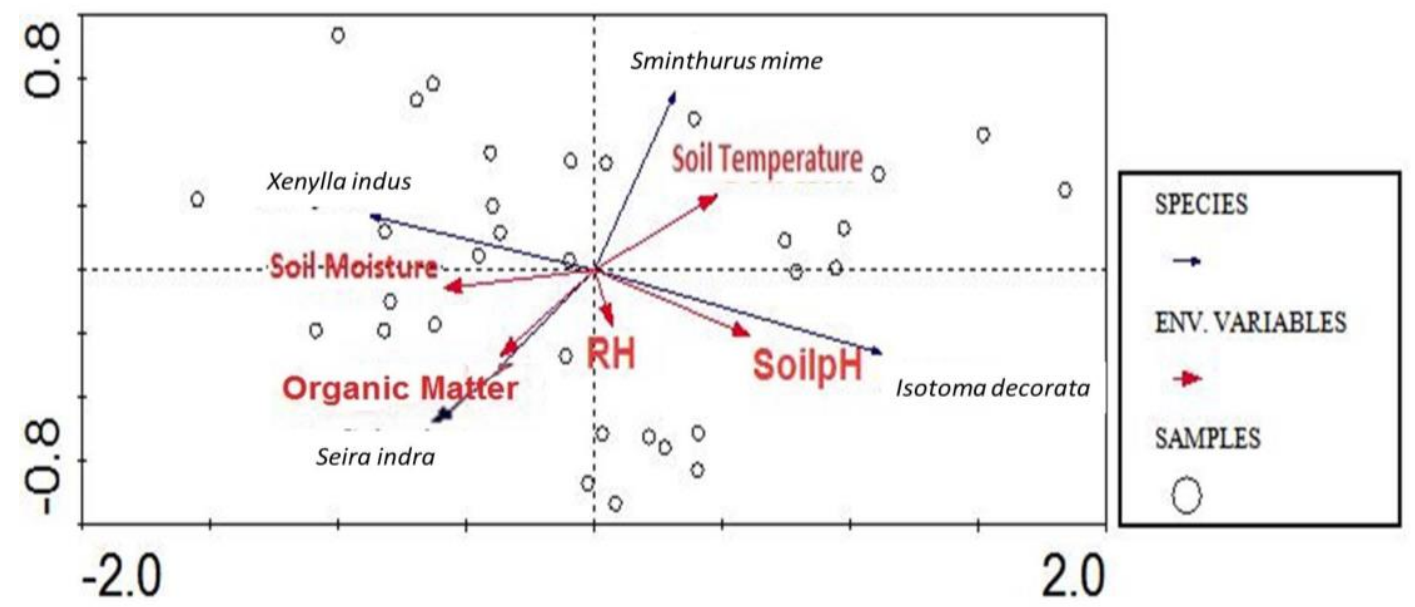

Figure 6. Principal component analysis ordination diagram of axis $1 \mathrm{X}$ axis 2 with species, environmental variables and sample.

\section{DISCUSSION}

The significant influence of crop type on the population abundance of Collembola has been observed in the present studies. The highest mean abundance of Collembola was found in Clover and also significantly different from the abundance means in other crops. The abundance in cotton and wheat had non-significant difference between each other but significantly less than in clover and sugarcane. Similarly, Shakir and Ahmed (2014) reported that per sample abundance of Collembola was higher in alfalfa followed by sugarcane and cotton while lowest in wheat. Contrary, Bandyopadhyaya et al. (2002) reported more population of Collembola in wheat and rice crops as compared to the jute. This effect may be due to the agronomic practices. The type of vegetation cover, abiotic factors and agricultural practices affect significantly on the population dynamics of Collembola. The effect of vegetation type and agricultural practices on the Collembola is often related with the quantity and quality of litter and the physical effects of vegetation cover on the soil microclimate and surface (Swift and Anderson, 1994; Hansen, 2000; Abbas, 2012).

The present studies have indicated a positive correlation of Collembola abundance with soil moisture in sugarcane, cotton, wheat and clover. The abundance of Collembola was positively correlated with soil moisture (Choi et al., 2006; Schultz et al., 2006; Kardol et al., 2011; Abbas and Parwez, 2012). The low contents of soil moisture not only reduced the activity and movement of Collembola but also reproduction as well (Choi et al., 2002). The high moisture contents in clover may have a limiting effect on the Collembola and weak correlation between abundance and soil moisture was, therefore, found.

The abundance of Collembola was negatively correlated with the soil temperature in sugarcane, cotton and clover while positive correlation was observed in wheat crop. Soil temperature was negatively correlated with the abundance of Collembola (Bandyopadhyaya et al., 2002; Parwez and Sharma, 2004; Kardol et al., 2011). These finding are contradictory to that of Frampton et al. (2001) and Karoline et al. (2010) who have reported that the abundance of Collembola was positively correlated with the soil temperature. The low soil temperature in wheat may be responsible for the low abundance of Collembola and strong positive correlation was found. Asikidis and Stamou (1991) have also reported that a drop in temperature can also result in decreasing the population densities of soil fauna. Sulkava and Huhta (2003) reported similar results of the effects of extremely low soil temperature in winter on the soil fauna.

Relative humidity showed the positive correlation with Collembola abundance in sugarcane and cotton while negative correlation was observed in clover and wheat crop. The low abundance of Collembola in cotton may be due to the low relative humidity and weak positive correlation was found. The results of the present study are in partial accordance with the work of Gope and Ray (2012) who have reported that relative humidity, had a significant effect and was positively correlated with the population abundance of Collembola.

Organic matter content of the soil was positively correlated with the abundance of Collembola in all the crops studied. High organic matter content of the soil had a significant influence in supporting the high population abundance of Collembola (Mussury et al., 2002; Muturi et al., 2009; Karoline et al., 2010). The high organic matter content of soil in clover may have a restraining effect on the Collembola and weak correlation between abundance and organic matter was found.

The findings of the study showed positive correlation of Collembola abundance with soil $\mathrm{pH}$ only in cotton crop 
while negative correlation was observed in sugarcane, clover and wheat. The high abundance of Collembola in clover and sugarcane may be due to low $\mathrm{pH}$ of soil and strong negative correlation was found. The abundance of Collembola was negatively correlated with the soil $\mathrm{pH}$ at two sites i.e. forest and agricultural land (Begum et al., 2011; Begum et al., 2014).

The changes in weather conditions affect the characteristics of soil which ultimately lead to changes in the abundance of Collembola in agroecosystems. The correlations observed in the present research were crop specific. Studies encompassing agronomic crops ecosystem are not reported previously, thus, the results of the present studies with regard to relationship between Collembola and abiotic factors were not possible to compare. However, Shakir and Ahmed (2014) have reported that soil temperature, relative humidity and organic matter may be linked with dynamics of collembolans in agro-ecosystem.

Generally, it is considered that the abundance of Collembola is high in soils having high moisture contents and adequate amount of organic matter, however, in the present study organic matter did not play a vital role. The conflicting results of high organic matter reported elsewhere have not supported the findings described here. The reduction in the abundance of Collembola under the scenarios of climate change, global warming and in fields that are dry particularly due to less supply of irrigation water (a big issue in Pakistan) may be reasons for adaptations in Collembola. Farming practices, adapted according to the climate change, are also the major cause of disturbance in the diversity of soil fauna. However, it is supposed that these soil arthropods being fittest can adjust to these changes successfully.

\section{REFERENCES}

Abbas, M.J. 2012. Seasonal diversity of Collembola assemblages in two different habitats of Aligarh. Indian J. Fund. Appl. Life Sci. 2:18-25.

Abbas, M.J. and H. Parwez. 2012. Impact of edaphic factors on the diversity of soil microarthropods in an agricultural ecosystem at Aligarh. Indian J. Fund. Appl. Life Sci. 2:185-191.

Ashraf, M. 1966. Studies on the ecology and biology of some of the soil Collembola. Ph.D. Diss., Dept. Zoology, Univ. Punjab, Lahore.

Asikidis, M. and G. Stamou. 1991. Spatial and temporal patterns of an Oribatid mite community in an evergreensclerophyllus formation (Hortiatis, Greece). Pedobiolgia 35:53-63.

Bandyopadhyaya, I., D.K. Choudhuri and J.F. Ponge. 2002. Effects of some physical factors and agricultural practices on Collembola in a multiple cropping programme in West Bengal (India). Eur. J. Soil Biol. 38: 111-117.
Bates, R.G. 1954. Electrometric pH Determination. John Willeys and Sons, Inc. New York.

Bauer, R. and E. Christian. 1993. Adaptations of three springtail species to granite boulder habitats (Collembola). Pedobiolgia 37:280-290.

Begum, F., R.M. Bajracharya, S. Sharma and B.K. Sitaula. 2011. Assessment of soil quality using microarthropod communities under different land system: A case study in the mid-hills of central Nepal. J. Life Sci. 5:66-73.

Begum, F., R.M. Bajracharya, B.K. Sitaula, S. Sharma, S. Ali and H. Ali. 2014. Seasonal dynamics and land use effect on soil microarthropod communities in the midhills of Nepal. Int. J. Agron. Agri. Res. 5: 114-123.

Brahmam, P., C. Sravanthy, P. Laxman, C. Samatha and C. Sammaiah. 2010. Biodiversity of soil arthropods in Btcotton fields of Warangal, Andhra Pradesh, India. Bioscan 5:159-160.

Choi, W.I., M.I. Ryoo and J. Kim. 2002. Biology of Paronychiurus kimi (Collembola: Onychiuridae) under the influences of temperature, humidity and nutrition. Pedobiolgia 46:548-557.

Choi, W., D.L. Moorhead, D.A. Neher and M. Ryoo. 2006. A modeling study of soil temperature and moisture effects on population dynamics of Paronychiurus kimi (Collembola: Onychiuridae). Biol. Fert. Soils 43:69-75.

Decaens, T., J.J. Jimenez, C. Gioia, G. Measey and P. Lavelle. 2006. The values of soil animals for conservation biology. Eur. J. Soil Biol. 42:23-38.

Ferguson, S.H. and D.O. Joly. 2002. Dynamics of springtail and mite populations: the role of density dependence, predation, and weather. Ecol. Entomol. 27:565-573.

Frampton, G.K., P.J. Van den Brink and S.D. Wratten. 2001. Diel activity patterns in an arable collembolan community. Appl. Soil Ecol. 17: 63-80.

Gope, R. and D.C. Ray. 2012. Seasonal distribution of Isotomina thermophilan in a secondary succession and a homegarden in Cachar, Assam. J. Environ. Biol. 33: 181-186.

Hammer, O., D. Harper and P. Ryan. 2001. Past: Paleontological statistics software package for education and data analysis. Paleontol. Electron. 4:1-9.

Hansen, R.A. 2000. Effects of habitat complexity and composition on a diverse litter microarthropod assemblage. Ecology 81:1120-1132.

Hopkin, S.P. 1997. Biology of the Springtails (Insecta: Collembola). Oxford University Press, Oxford.

Jucevica, E. and V. Melecis. 2006. Global warming affect Collembola community: A long-term study. Pedobiologia 50: 177-184.

Kanal, A. 2004. Effects of fertilization and edaphic properties on soil-associated Collembola in crop rotation. Agron. Res. 2:153-168.

Karoline, U., J. Frouz and T. Drapela. 2010. Distribution patterns of Collembola affected by extensive grazing in 
different vegetation types. $19^{\text {th }}$ World Congress of Soil Science, Soil Solutions for a Changing World 1-6 August 2010, Brisbane, Australia.

Kardol, P., W.N. Reynolds, R.J. Norby and A.T. Classen. 2011. Climate change effects on soil microarthropod abundance and community structure. Appl. Soil Ecol. 47:37-44.

Ke, X., Y.M. Yang, W.Y. Yin and L.Z. Xue. 2004. Effects of low pH environment on the collembolan Onychiurus yaodai. Pedobiolgia 48:545-550.

Lensing, J.R., S. Todd and D.H. Wise. 2005. The impact of altered precipitation on spatial stratification and activity-densities of springtails (Collembola) and spiders (Araneae). Ecol. Entomol. 30:194-200.

Loring, S.J. 1981. Response of Hypogastrura nivicola (Collembola: Hypogastruridae) to variable relative humidity. Pedobiolgia 22:167-171.

Masud, S.A. 1971. Taxonomy of some Collembola at Lyallpur. M.Sc. Diss. Dept. Entomol., West Pak. Agri. Univ. Lyallpur, Pakistan.

Mussury, R.M., S.P.Q. Scalon, S.V. Silva and V.R. Soligo. 2002. Study of Acari and Collembola populations in four cultivation systems in Dourados-MS. Braz. Arch. Biol. Technol. 45:257-264.

Muturi, J.J., J.P. Mbugi, J.M. Mueke, J. Lagerlof, J.K. Mungatu, D. Nyamasyo and M. Gikungu. 2009. Collembola density and diversity along a gradient of land-use types in Embu district, Eastern Kenya. Trop. Subtrop. Agroecosyst. 11:361-369.

Parwez, H. and M.K. Sharma. 2004. Dynamics of the collembolan population in two different ecotypes in a tropical reson. Biosci. Res. Bull. 20:27-38.

Paul, D. and A. Nongmaithem. 2011. Collembolan density and diversity in a forest and an agro ecosystem. Open J. Soil Sci. 1:54-60.

Phoofolo, M.W., K.L. Giles and N.C. Elliott. 2010. Effects of relay-intercropping sorghum with winter wheat, alfalfa, and cotton on lady beetle (Coleoptera: Coccinellidae) abundance and species composition. Environ. Entomol. 39:763-774.

Pineda, S., G. Cruz, J. Valle, J.F. De La Rosa, J. Chavarrieta, M. Ordonez-Resendiz and A. Martinez. 2012. Arthropod abundance in two maize fields in western central Mexico. J. Kansas Entomol. Soc. 85:340-352.

Pflug, A. and V. Wolters. 2001. Influence of drought and litter age on Collembola communities. Eur. J. Soil Biol. 37:305-308.

Qadeer, A. 1974. Further studies on Collembola of Lyallpur. M.Sc. Diss. Dept. Entomol., Agri. Univ. Lyallpur, Pakistan.

Reynolds, S. 1970. Gravimetric method of soil moisture determination. Part I-III. J. Hydrol. 11:258-300.
Sajjad, A., F. Ahmad, A.H. Makhdoom and A. Imran. 2012. Does trash burning harm arthropod biodiversity in sugarcane. Int. J. Agri. Biol. 14:1021-1023.

Schultz, B.J., J.R. Lensing and D.H. Wise. 2006. Effects of altered precipitation and wolf spiders on the density and activity of forest-floor Collembola. Pedobiologia 50: 43-50.

Schumacher, B.A. 2002. Methods for the determination of total organic carbon (TOC) in soils and sediments. U.S. Environmental Protection Agency: Washington D.C. Available online at http://www.epa.gov/esd/cmb/research/papers/bs116.pdf

Shakir, M.M. and S. Ahmed. 2014. Seasonal abundance of soil arthropods in relation to meteorological and edaphic factors in the agroecosystems of Faisalabad, Punjab, Pakistan. Int. J. Biometeorol. 59:605-616.

Silva, E., J. Franco, T. Vasconcelos and M. Branco. 2010. Effect of ground cover vegetation on the abundance and diversity of beneficial arthropods in citrus orchards. Bull. Entomol. Res. 100:489-499.

Sousa, J.P., M.M. da Gama, C. Pinto, A. Keating, F. Calhoa, M. Lemos, C. Castro, T. Luz, P. Leitao and S. Dias. 2004. Effects of land-use on Collembola diversity patterns in a mediterranean landscape. Pedobiologia 48:609-622.

Statgraphics. 2009. Statgraphics Centurion, Version 16.0. 09, 1982-2009, Statpoint technologies. Inc. Warrenton, Virginia, ZDA.

StatSoft. 2011. Statistica, V. 10.0. StatSoft, Inc. Tulsa, Okla.

Suleman, M. and G. Jan. 1981. Studies on soil fauna with particular reference to soil arthropods of Peshawar University Campus III. Seasonal effects on vertical distribution of Acarina and Collembola. J. Sci. Technol. 5:52-59.

Sulkava, P. and V. Huhta. 2003. Effects of hard frost and freeze-thaw cycles on decomposer communities and $n$ mineralization in boreal forest soil. Appl. Soil Ecol. 22:225-239.

Swift, M. and J. Anderson. 1994. Biodiversity and ecosystem function in agricultural systems, p.15-41. In: Biodiversity and Ecosystem Function. Springer Berlin Heidelberg.

Ter Braak, C. and P. Smilauer. 2002. Canoco for windows version 4.5. Biometris-Plant Research International, Wageningen.

$\mathrm{Vu}$, Q.M. and T.T. Nguyen. 2000. Microarthropod community structures (Oribatei and Collembola) in Tam Dao national park, Vietnam. J. Bioscience 25:379-386.

Wolters, V. 1998. Long-term dynamics of a collembolan community. Appl. Soil Ecol. 9: 221-227.

Xu, G.L., P. Schleppi, M.H. Li and S.L. Fu. 2009. Negative responses of Collembola in a forest soil (Alptal, Switzerland) under experimentally increased $n$ deposition. Environ. Pollut. 157:2030-2036. 
Zhimomi, V., M. Ao and D. Chaturvedi. 2009. Seasonal abundance of major groups of and their correlation with abiotic factors in rice ecosystem. Int. J. Agri. Environ. Biotechnol. 2:289-293.
Zhu, X., B. Gao, S. Yuan and Y. Hu. 2010. Community structure and seasonal variation of soil arthropods in the forest-steppe ecotone of the mountainous region in Northern Hebei, China. J. Mountain Sci. 7:187-196. 